\title{
Penerapan Artificial Neural Network (ANN) untuk Memprediksi Perubahan Derajat Miopia pada Manusia
}

\author{
Ni Kadek Emik Sapitri \\ Program Studi Matematika, Fakultas MIPA, Universitas Udayana \\ e-mail:emikpitri@gmail.com \\ I Putu Eka N. Kencana \\ Program Studi Matematika, Fakultas MIPA, Universitas Udayana \\ e-mail: i.putu.enk@unud.ac.id \\ Luh Putu Ida Harini \\ Program Studi Matematika, Fakultas MIPA, Universitas Udayana \\ e-mail: ballidah@unud.ac.id
}

\begin{abstract}
Myopia is a vision disorder that causes the sufferers unable to see distant objects. The degree of myopia in humans can changes, both increasing and decreasing. The increasing of myopia degree is proportional to the potential of other visual disorders, such as cataracts, retinal detachment, and glaucoma. Therefore, the increasing of myopia degree needs to be watched out. Several previous studies only considered the time factor in predicting the changes of myopia degree. In fact, the changes of myopia degree also influenced by some factors that related to individual identity and behavior. This study aims to predict the changes of myopia degree in humans based on some factors that causes myopia. This study uses data that has been scaled with the fuzzy membership function to be processed with ANN for predicting the changes of myopia degree. By ANN 6-2-3 architecture that uses 80 training data, 20 testing data, and 1 predictive data, the prediction result of the changes of myopia degree in the right eye is 1.1 dioptri, in the left eye is 1.2 dioptri and the accumulated of both is 2.3 dioptri with accuration values $87.79 \%, 78.47 \%$, and $83.21 \%$.
\end{abstract}

Keywords: ANN, factors that causes myopia, fuzzy membership function, myopia, prediction

Abstrak: Miopia merupakan gangguan penglihatan yang menyebabkan penderitanya tidak dapat melihat objek yang jauh dengan jelas. Derajat miopia seseorang dapat mengalami perubahan, baik itu meningkat maupun menurun. Peningkatan derajat miopia berbanding lurus dengan potensi terjangkit gangguan penglihatan lainnya, seperti katarak, ablasi retina, dan glaukoma. Oleh karena itu, peningkatan derajat miopia perlu diwaspadai. Beberapa penelitian sebelumnya hanya memperhitungkan faktor waktu dalam 
memprediksi perubahan derajat miopia. Padahal, perubahan derajat miopia juga dipengaruhi oleh beberapa faktor yang berkaitan erat dengan identitas dan perilaku individu yang bersangkutan. Penelitian ini bertujuan untuk memprediksi perubahan derajat miopia pada manusia berdasarkan beberapa faktor penyebab miopia. Penelitian ini menggunakan data yang telah di-scaling dengan fungsi keanggotaan fuzzy untuk diolah dengan ANN dalam proses memprediksi perubahan derajat miopia. Dengan arsitektur ANN 6-2-3 yang menggunakan 80 data latih, 20 data validasi, dan 1 data uji, diperoleh hasil prediksi perubahan derajat miopia mata kanan sebesar 1.1 dioptri, mata kiri 1.2 dioptri dan diakumulasi keduanya adalah 2.3 dioptri, dengan persentase akurasi berturut-turut sebesar $87.79 \%$, $78.47 \%$, dan $83.21 \%$.

Kata Kunci: ANN, faktor-faktor penyebab miopia, fungsi keanggotaan fuzzy, miopia, prediksi

\section{Pendahuluan}

Miopia atau rabun jauh merupakan gangguan pengelihatan yang terjadi ketika bayangan objek yang jauh jatuh di depan retina (Williams et al., 2015). Akibatnya, penderita miopia tidak dapat melihat objek yang jauh dengan jelas.

Derajat miopia dinyatakan dalam satuan Dioptri (D) yang merupakan satuan untuk mengukur kekuatan pemfokusan dari lensa kacamata yang dibutuhkan oleh penderita miopia agar bayangan objek kembali jatuh tepat pada retina. Derajat miopia seseorang dapat mengalami perubahan, baik itu meningkat maupun menurun. Peningkatan derajat miopia berbanding lurus dengan potensi terjangkit gangguan pengelihatan, misalnya katarak, ablasi retina, dan glaukoma (Holden et al., 2016). Oleh karena itu, peningkatan derajat miopia perlu diwaspadai.

Terdapat beberapa penelitian terkait perubahan derajat miopia. Penelitian oleh Greene, et al., (2015) menemukan bahwa kacamata baca dapat mengurangi peningkatan derajat miopia di kalangan mahasiswa pilot di Annapolis. Pada penelitian tersebut, Greene membandingkan metode regresi linear, exponential progression, dan fungsi Gompertz, untuk menghitung peningkatan derajat miopia terhadap satuan waktu saat mahasiswa telah memakai kacamata baca.

Medina (2015) berhasil memodelkan miopia pada manusia berdasarkan panjang aksial lensa sebagai sistem emetropisasi kontrol umpan balik. Hasilnya, peningkatan derajat miopia dalam satuan waktu dapat diprediksi dengan model kontrol umpan balik.

Penelitian lainnya oleh Greene \& Medved (2017) berhasil menstimulasikan perkembangan miopia dengan analogue computer model berupa sebuah sirkuit listrik. Model tersebut menunjukkan perubahan derajat miopia berada dalam kisaran -0,5 Dioptri per tahun yang diperoleh dengan menetapkan konstanta waktu sebesar 60 s.d. 100 hari. 
Keseluruhan penelitian tersebut secara umum hanya mempertimbangkan perubahan derajat miopia terhadap faktor waktu. Padahal, perubahan derajat miopia tidak hanya dipengaruhi oleh waktu, namun juga dipengaruhi oleh faktor-faktor penyebab miopia. Beberapa penelitian menunjukan bahwa perubahan derajat miopia dapat disebabkan oleh berbagai faktor, di antaranya aktivitas pada jarak dekat, pendidikan dan penghasilan, aktivitas luar ruangan, umur, ras atau etnis, genetika, dan riwayat miopia orang tua (Klein, 2010). Dapat dipahami bahwa faktor-faktor tersebut berkaitan erat dengan identitas dan perilaku individu yang bersangkutan. Memperhatikan keterbatasan penelitian-penelitian sebelumnya serta adanya faktor-faktor yang menjadi penyebab miopia, maka penelitian ini bertujuan untuk memprediksi perubahan derajat miopia seseorang berdasarkan faktor-faktor penyebab miopia.

Memperhatikan belum adanya penelitian yang dapat memastikan seberapa kuat peran masing-masing faktor penyebab miopia dalam peristiwa perubahan derajat miopia seseorang dalam kurun waktu tertentu, maka tidak dapat dipastikan berapa dioptri derajat miopia seseorang dapat berubah dalam kurun waktu tertentu akibat masing-masing faktor penyebab miopia tersebut. Dengan demikian, diperlukan suatu metode yang dapat mempelajari pola perubahan derajat miopia masing-masing individu terhadap faktor-faktor penyebab miopia. Oleh karena itu, penelitian ini akan memprediksi perubahan derajat miopia seseorang berdasarkan faktor-faktor penyebab miopia menggunakan artificial neural network (ANN). Hal ini dikarenakan ANN dapat dimanfaatkan untuk mempelajari pola-pola dari data input dan data output yang sudah ada untuk memprediksi suatu target saat dimasukkan data baru (Kusumadewi, 2004).

Pada penelitian ini digunakan enam buah variabel input berupa faktor-faktor penyebab miopia dan tiga buah variabel output berupa perubahan derajat miopia pada mata kanan, perubahan derajat miopia pada mata kiri, dan akumulasi keduanya. Seluruh data pada masing-masing variabel tersebut merupakan data primer yang diperoleh dengan menyebarkan kuesioner daring. Data primer tersebut terlebih dahulu di-scaling dengan fungsi keanggotaan fuzzy dan kemudian diolah dengan ANN untuk memprediksi perubahan derajat miopia pada manusia.

ANN adalah suatu model komputasi yang terinspirasi dari jaringan syaraf biologis. ANN terdiri dari elemen pemrosesan (neuron) dan koneksi antarneuron dengan koefisien (bobot) yang terikat pada koneksi tersebut (Shanmuganathan, 2016). Pada penelitian ini, beberapa arsitektur ANN yang akan diujikan ditetapkan dengan mempertimbangkan rules of thumb. Rules of thumb merupakan petunjuk untuk menentukan banyaknya neuron digunakan pada hidden layer (Heaton, 2008). Beberapa arsitektur ANN tersebut selanjutnya akan dilatih dan divalidasi sehingga mendapatkan arsitektur terpilih yang akan digunakan untuk memprediksi perubahan derajat miopia tersebut. 
Arsitektur ANN yang terpilih diharapkan dapat menghasilkan prediksi yang akurat, sehingga masyarakat khususnya penderita miopia dapat mengetahui seberapa tinggi peningkatan atau penurunan derajat miopia mereka dalam kurun waktu tertentu apabila berkaca dari tindakan mereka saat ini.

\section{Metode Penelitian}

\subsection{Jenis dan Sumber Data}

Data yang digunakan dalam penelitian ini merupakan data primer. Populasi dalam penelitian ini adalah penderita miopia di Indonesia yang sudah pernah mengganti kacamatanya. Sementara itu, sampel pada penelitian ini ditetapkan sebanyak 101 orang.

Segala informasi pada setiap variabel ditanyakan dengan menggunakan kuesioner. Pengumpulan data melalui kuesioner dilakukan secara daring dengan google form. Data yang terkumpul selanjutnya dipilah menjadi data siap olah yang terdiri atas variabel penelitian sesuai Tabel 1 .

Tabel 1. Variabel Penelitian

\begin{tabular}{|c|c|c|c|}
\hline Variabel & Keterangan & Satuan & Skala \\
\hline \multicolumn{4}{|c|}{ Variabel Input } \\
\hline$x_{1}$ & Umur & Tahun & Rasio \\
\hline$x_{2}$ & $\begin{array}{l}\text { Riwayat miopia orang tua }(1=\text { keduanya penderita } \\
\text { miopia; } 0,5=\text { salah satunya penderita miopia; } 0= \\
\text { keduanya bukan penderita miopia })\end{array}$ & - & Ordinal \\
\hline$x_{3}$ & $\begin{array}{l}\text { Lama aktivitas membaca buku dan media cetak } \\
\text { lainnya dalam sehari }\end{array}$ & Jam & Rasio \\
\hline$x_{4}$ & $\begin{array}{l}\text { Lama aktivitas menatap layar perangkat elektronik } \\
\text { dalam sehari }\end{array}$ & Jam & Rasio \\
\hline$x_{5}$ & Lama kegiatan di luar ruangan dalam sehari & Jam & Rasio \\
\hline$x_{6}$ & Rentang waktu penggantian kacamata & Tahun & Rasio \\
\hline \multicolumn{4}{|c|}{ Variabel Output } \\
\hline$y_{1}$ & Perubahan derajat miopia pada mata kanan & Dioptri & Rasio \\
\hline$y_{2}$ & Perubahan derajat miopia pada mata kiri & Dioptri & Rasio \\
\hline$y_{3}$ & $\begin{array}{l}\text { Akumulasi perubahan derajat miopia pada mata } \\
\text { kanan dan kiri }\end{array}$ & Dioptri & Rasio \\
\hline
\end{tabular}




\subsection{Metode Analisis Data}

Setelah melakukan pemilahan data sesuai variabel penelitian, selanjutnya akan dilakukan tahapan analisis data sebagai berikut:

1. Tahap scaling data: Melakukan studi pustaka untuk memilih dan menentukan rumus fungsi keanggotaan fuzzy berdasarkan kecenderungan hubungan masing-masing variabel $x$ dengan $y$ di kehidupan nyata. Kemudian, fungsi tersebut digunakan untuk menghitung derajat keanggotaan setiap data di masing-masing variabel yang diteliti. Penghitungan derajat keanggotaan akan memanfaatkan Microsoft Office Excel 2013;

2. Tahap penentuan beberapa arsitektur ANN yang akan diujikan: Menentukan beberapa arsitektur ANN yang akan diujikan. Arsitektur ANN yang akan diujikan memiliki 6 neuron input, 3 neuron output, dengan variasi jumlah neuron pada hidden layer berpedoman pada rules of thumb;

3. Tahap pemilihan fungsi aktivasi dan kondisi berhenti: Memilih fungsi aktivasi yang akan digunakan dan menentukan kondisi berhenti yang diinginkan pada algoritma backpropagation yang digunakan untuk melatih dan menguji setiap arsitektur ANN;

4. Tahap pembagian data: Membagi 101 data menjadi data latih, data validasi, dan data uji. Penelitian ini menggunakan 80 data latih, 20 data validasi, dan 1 data uji;

5. Tahap pemilihan arsitektur ANN:

Tahap ini dilakukan dengan software JupyterLab 1.2.6 yang memakai bahasa pemrograman Python dengan koding program berpedoman pada Welch (2015). Langkah-langkah yang dilakukan dapat diuraikan sebagai berikut:

a. Menerapkan algoritma pembelajaran backpropagation pada proses pelatihan dan validasi beberapa arsitektur ANN yang telah ditentukan pada tahap ke-2. Pelatihan dan validasi dilakukan sebanyak 3 kali percobaan;

b. Perhatikan nilai cost function yang didapat pada tahap pelatihan pada setiap iterasi ke-t $\left(J_{l}(t)\right)$ dan nilai cost function yang didapat pada tahap validasi pada setiap iterasi ke-t $U_{v}(t)$ ) pada arsitektur ANN yang bersangkutan pada ketiga percobaan. Jika pada minimal satu percobaan terdapat kondisi $I_{v}(t)>J_{l}(t)$, maka arsitektur ANN yang bersangkutan dianggap mengalami overfitting. Hal ini berdasarkan penjelasan pada penelitian Badieah dkk., (2016) yang menyatakan bahwa overfitting menyebabkan kinerja arsitektur ANN bernilai baik saat proses pelatihan namun buruk pada proses validasi. Overfitting terjadi ketika algoritma pembelajaran pada ANN dijalankan dalam jumlah iterasi yang relatif besar atau arsitektur ANN terlalu kompleks untuk masalah atau jumlah data yang tersedia (Panchal et al., 2011). 
Selanjutnya, lakukan salah satu dari poin c, d, dan e di bawah ini sesuai kondisi yang diperoleh;

c. Jika semua arsitektur ANN mengalami overfitting, maka lakukan weight penalty dengan menggunakan konstanta penalty $\lambda=0.0001$. Selanjutnya, pilih arsitektur ANN yang tidak mengalami overfitting dan memiliki rataan nilai MSE paling kecil dengan nilai paling stabil setelah menerapkan weight penalty sebagai arsitektur terbaik pada penelitian ini. Nilai paling stabil yang dimaksud yaitu tidak memiliki perbedaan nilai yang besar pada ketiga percobaan yang dilakukan.

Rataan nilai MSE tersebut dihitung dengan rumus berikut:

$$
\text { Rataan Nilai } M S E=\frac{1}{3} \sum_{i=1}^{3}\left(M S E y_{i}\right)
$$

dengan $M S E y_{i}$ merupakan nilai MSE pada variabel output $y_{i}$. Sementara itu, nilai $M S E y_{i}$ tersebut dihitung dengan rumus berikut:

$$
\text { MSE } y_{i}=\frac{1}{d} \sum_{n=1}^{d}\left(y_{n}-\hat{y}_{n}\right)^{2}
$$

dengan $d$ menyatakan banyak data, $y_{n}$ menyatakan target output ke-n, dan $\hat{y}_{n}$ menyatakan hasil prediksi target output ke-n;

d. Jika ada lebih dari satu arsitektur ANN yang tidak mengalami overfitting, maka pilih arsitektur yang memiliki rataan nilai MSE paling kecil dan paling stabil di antara arsitektur ANN yang tidak mengalami overfitting tersebut sebagai arsitektur terbaik pada penelitian ini;

e. Jika hanya ada satu arsitektur ANN yang tidak mengalami overfitting, maka arsitektur tersebut otomatis terpilih sebagai arsitektur terbaik pada penelitian ini.

6. Tahap memprediksi: Menggunakan arsitektur ANN terbaik yang terpilih pada tahap ke-5 untuk memprediksi perubahan derajat miopia. Prediksi dilakukan dengan cara memasukkan data uji yang terpilih pada tahap ke-4 pada arsitektur ANN yang telah terpilih pada tahap ke-5. Percobaan yang akan dilanjutkan untuk tahap memprediksi ini ialah salah satu dari ketiga percobaan yang memiliki rataan nilai MSE terkecil pada arsitektur terbaik;

7. Tahap un-scaling hasil prediksi: Mengembalikan bentuk hasil prediksi dari bentuk derajat keanggotaan fuzzy ke bentuk bilangan real menggunakan fungsi keanggotaan fuzzy yang terpilih untuk masing-masing variabel $y$ pada tahap ke-1;

8. Tahap penghitungan akurasi hasil prediksi: Menghitung persentase error hasil prediksi pada masing-masing variabel output yang diperoleh dengan arsitektur ANN yang terpilih dengan rumus:

$$
E_{i}=\left|\frac{y_{i}-\hat{y}_{i}}{y_{i}}\right| \times 100 \%
$$


dengan $i=1,2,3$; $E_{i i}$ menyatakan persentase error pada output ke-i, $y_{i}$ menyatakan data output ke-i sebelum di-scaling, dan $\hat{y}_{i}$ menyatakan hasil prediksi output ke-i setelah un-scaling.

\section{Hasil dan Pembahasan}

Pengumpulan data dengan kuesioner daring dilakukan selama 40 hari yaitu pada tanggal 5 Februari 2020 sampai dengan 16 Maret 2020. Diperoleh data terpilih sebanyak 101 data. Responden kuesioner tersebut berasal dari 22 provinsi di Indonesia, terdiri dari 79 perempuan dan 22 laki-laki dengan rentangan umur 14 s.d. 54 tahun.

Setelah memilah data berdasarkan variabel penelitian, selanjutnya akan dilakukan langkah-langkah sesuai tahapan analisis data

\subsection{Scaling Data}

Berdasarkan studi pustaka beberapa literatur berikut: Bethesda et al., (1996), Vitale et al., (2008), Kusumadewi \& Purnomo (2010), BPS (2013), Lim et al., (2014), Saxena et al., (2015), Saxena et al., (2017), Theophanous et al., (2018), dan Huang et al., (2019), diperoleh rumus-rumus fungsi keanggotaan fuzzy yang cocok untuk menghitung derajat keanggotaan data di masing-masing variabel agar menggambarkan hubungan masing-masing variabel $x$ dengan $y$ di kehidupan nyata yaitu:

a. Rumus scaling variabel $x_{1}$ :

$$
\mu\left(x_{1} ; 14,34,54\right)=\left\{\begin{array}{cl}
0 & ; j i k a x_{1}<14 \\
2\left(\frac{x_{1}-14}{40}\right)^{2} & ; j i k a 14 \leq x_{1}<34 \\
1-2\left(\frac{54-x_{1}}{40}\right)^{2} & ; j i k a \quad 34 \leq x_{1}<54 \\
1 & \text {; jika } x_{1} \geq 54
\end{array}\right.
$$

b. Rumus scaling variabel $x_{2}$ :

$$
\mu\left(x_{2}\right)=\left\{\begin{array}{l}
0 ; j i k a x_{2}<0 \\
x_{2} ; j i k a 0 \leq x_{2}<1 \\
1 ; j i k a x_{2} \geq 1
\end{array}\right.
$$

c. Rumus scaling variabel ${ }^{x_{3}}$ : 
Emik Sapitri, Eka N. Kencana, Ida Harini/Penerapan ANN dalam Memprediksi Miopia

$$
\mu\left(x_{3} ; 0,5,10\right)=\left\{\begin{array}{cl}
0 & \text {;jika } x_{3}<0 \\
2\left(\frac{x_{3}}{10}\right)^{2} & \text {;jika } 0 \leq x_{3}<5 \\
1-2\left(\frac{10-x_{3}}{10}\right)^{2} & \text {;jika } 5 \leq x_{3}<10 \\
1 & \text {;jika } x_{3} \geq 10
\end{array}\right.
$$

d. Rumus scaling variabel $x_{4}$ :

$$
\mu\left(x_{4} ; 1,9.5,18\right)=\left\{\begin{array}{cl}
0 & \text {;jika } x_{4}<1 \\
2\left(\frac{x_{4}-1}{17}\right)^{2} & \text {;jika } 1 \leq x_{4}<9.5 \\
1-2\left(\frac{18-x_{4}}{17}\right)^{2} & \text {;jika } 9.5 \leq x_{4}<18 \\
1 & \text {;jika } x_{4} \geq 18
\end{array}\right.
$$

e. Rumus scaling variabel ${ }^{x_{5}}$ :

$$
\mu\left(x_{5} ; 0,7.5,15\right)=\left\{\begin{array}{cl}
1 & \text {;ika } x_{5}<0 \\
1-2\left(\frac{x_{5}}{15}\right)^{2} & \text {; jika } 0 \leq x_{5}<7.5 \\
2\left(\frac{15-x_{5}}{15}\right)^{2} & \text {; jika } 7.5 \leq x_{5}<15 \\
0 & \text {; jika } x_{5} \geq 15
\end{array}\right.
$$

f. Rumus scaling variabel ${ }^{x_{6}}$ :

$$
\mu\left(x_{6}\right)=\left\{\begin{array}{c}
0 ; j i k a x_{6}<0 \\
\frac{x_{6}}{70.9} ; j i k a 0 \leq x_{6}<70.9 \\
1 ; j i k a x_{6} \geq 70.9
\end{array}\right.
$$

g. Rumus scaling variabel $y_{1}$ :

$$
\mu\left(y_{1}\right)=\left\{\begin{array}{c}
0 ; j i k a y_{1}<-0.5 \\
\frac{y_{1}+0.5}{8+0.5 ; j i k a-0.5 \leq y_{1}<8} \\
1 ; j i k a y_{1} \geq 8
\end{array}\right.
$$

h. Rumus scaling variabel $y_{2}$ :

$$
\mu\left(y_{2}\right)=\left\{\begin{array}{c}
0 ; j i k a y_{2}<-1.25 \\
\frac{y_{2}+1.25}{8+1.25 ; j i k a-1.25 \leq y_{2}<8} \\
1 ; j i k a y_{2} \geq 8
\end{array}\right.
$$

i. Rumus scaling variabel $y_{3}$ : 


$$
\mu\left(y_{3}\right)=\left\{\begin{array}{c}
0 ; \text { jika } y_{3}<-1.25 \\
\frac{y_{3}+1.25}{16+1.25} ; \text { jika }-1.25 \leq y_{3}<16 \\
1 ; \text { jika } y_{3} \geq 16
\end{array}\right.
$$

Rumus (4)-(12) tersebut selanjutnya digunakan untuk menghitung derajat keanggotaan data dengan memanfaatkan Microsoft Office Excel 2013. Dengan demikian, interval data yang beragam dapat diubah ke dalam interval yang seragam yaitu $[0,1]$. Data-data tersebut diolah lebih lanjut pada subbab 3.5 menggunakan ANN.

\subsection{Penentuan Beberapa Arsitektur ANN}

Pada tahap ini dilakukan pemilihan beberapa arsitektur ANN yang akan diujikan lebih lanjut pada bagian 3.5. Arsitektur ANN yang digunakan dalam penelitian ini memiliki 6 neuron input, 3 neuron output, dan variasi jumlah neuron pada hidden layer akan dipilih berdasarkan rules of thumb.

Enam neuron input pada arsitektur ANN merepresentasikan keenam variabel input. Sementara itu, tiga neuron output merepresentasikan ketiga variabel output. Lebih lanjut, untuk menentukan variasi jumlah neuron pada hidden layer, perhatikan ketiga rules of thumb berdasarkan Heaton (2008) halaman 153 berikut:

1. Rule nomor 1 menyatakan bahwa "banyak neuron pada hidden layer harus berada di antara ukuran input layer dan ukuran output layer". Perhatikan bahwa ukuran input layer ANN adalah 6 dan ukuran output layer adalah 3. Berdasarkan rules of thumb nomor 1 , banyak neuron pada hidden layer berada pada interval [3,6];

2. Rule nomor 2 menyatakan bahwa "jumlah neuron pada hidden layer harus sebanyak $\frac{2}{3}$

$\overline{3}$ ukuran input layer, ditambah ukuran output layer". Ini berarti, jumlah neuron pada hidden layer harus sebanyak $\left(\frac{2}{3} \times 6\right)+3=4+3=7$ neuron;

3. Rule nomor 3 menyatakan bahwa "banyak neuron pada hidden layer harus kurang dari dua kali ukuran input layer". Ini berarti, banyak neuron pada hidden layer harus kurang dari 12 neuron. Dikarenakan banyak neuron pada hidden layer haruslah merupakan elemen bilangan asli, maka banyak neuron pada hidden layer berada pada interval $[1,11]$.

Karena $[3,6] \subset[1,11]$ dan $7 \in[1,11]$, maka gabungan hasil dari ketiga rules of thumb adalah $[1,11]$. Dengan demikian, banyak neuron pada hidden layer berada dalam interval $[1,11]$. Oleh karena itu, pada 3.5 akan diujikan 11 arsitektur ANN yang me- 
miliki 6 neuron input dan 3 neuron output, dengan variasi jumlah neuron pada hidden layer sebanyak 1 s.d. 11 neuron.

\subsection{Pemilihan Fungsi Aktivasi dan Kondisi Berhenti}

Pada tahap ini dilakukan pemilihan fungsi aktivasi yang digunakan pada pada algoritma backpropagation dan menentukan kondisi berhenti yang diinginkan pada algoritma backpropagation. Sibi et al., (2013) menyatakan bahwa fungsi aktivasi sigmoid biner merupakan salah satu fungsi aktivasi yang banyak digunakan. Oleh karena itu, penelitian ini menggunakan fungsi aktivasi sigmoid biner dengan rumus:

$$
f(x)=\frac{1}{1+e^{-x}} \text { dengan } f^{\prime}(x)=f(x)[1-f(x)]
$$

Selanjutnya akan ditentukan kondisi berhenti yang diinginkan pada algoritma backpropagation. Algoritma backpropagation berhenti saat jumlah iterasi mencapai jumlah iterasi maksimum yang ditetapkan yaitu 40 iterasi.

\subsection{Pembagian Data}

Sebanyak 101 data yang digunakan dalam penelitian ini selanjutnya akan dibagi menjadi data latih, data validasi, dan data uji. Penelitian ini akan menggunakan 80 data latih, 20 data validasi, dan 1 data uji. Data latih dan data validasi tergolong data insample sementara data uji tergolong out-sample. Pembagian data dilakukan dengan memanfaatkan library train_test_split pada Python sehingga pemilihan dan urutan data yang dihasilkan bersifat acak.

Sebanyak 101 data yang telah di-scaling selanjutnya dibagi ke dalam 2 kelompok data terlebih dahulu. Kelompok pertama sebanyak 80 data yang ditetapkan sebagai data latih dan kelompok kedua sebanyak 21 data. Lebih lanjut, 21 data pada kelompok kedua tersebut dibagi ke dalam data validasi dan data uji, yaitu sebanyak 20 data validasi dan 1 data uji. Dengan demikian, diperoleh 80 data latih, 20 data validasi, dan 1 data uji.

\subsection{Pemilihan Arsitektur ANN Terbaik}

Sebanyak 11 arsitektur ANN yang diperoleh pada 3.2 kemudian dilatih dan divalidasi dengan algoritma backpropagation. Pelatihan dan validasi tersebut dilakukan menggunakan software JupyterLab 1.2.6.

Berdasarkan hasil yang diperoleh di setiap arsitektur ANN di setiap percobaan, tidak terdapat kondisi $I_{u}(t)>J_{l}(t)$. Hal ini mengindikasikan bahwa semua arsitektur ANN tersebut tidak mengalami overfitting. Dengan kata lain, ada lebih dari satu arsi- 
tektur ANN yang tidak mengalami overfitting. Oleh karena itu, selanjutnya dilakukan langkah 5d, yaitu memilih arsitektur ANN yang memiliki rataan nilai MSE paling kecil dengan nilai paling stabil di antara seluruh arsitektur ANN tersebut sebagai arsitektur terbaik pada penelitian ini.

Nilai MSE dihitung dengan persamaan (2). Nilai tersebut menggambarkan nilai error dari hasil prediksi masing-masing data output pada data validasi yang diperoleh pada iterasi terakhir (iterasi ke-40) saat proses validasi arsitektur ANN yang bersangkutan. Sementara itu, rataan MSE yang dihitung dengan persamaan (1) merupakan ratarata dari MSE ketiga output pada arsitektur ANN yang bersangkutan. Nilai rataan MSE setiap percobaan tercantum pada tabel 2 .

Tabel 2. Rataan Nilai MSE

\begin{tabular}{|c|c|c|c|}
\hline \multirow{2}{*}{ ANN } & \multicolumn{3}{|c|}{ Rataan Nilai MSE } \\
\cline { 2 - 4 } & Percobaan I & Percobaan II & Percobaan III \\
\hline $6-1-3$ & 6.029 & 5.862 & 6.655 \\
\hline $\mathbf{6 - 2 - 3}$ & $\mathbf{5 . 8 2 9}$ & $\mathbf{5 . 7 8 9}$ & $\mathbf{5 . 7 8 8}$ \\
\hline $6-3-3$ & 6.510 & 6.014 & 6.298 \\
\hline $6-4-3$ & 8.334 & 9.052 & 7.745 \\
\hline $6-5-3$ & 8.248 & 7.922 & 8.125 \\
\hline $6-6-3$ & 8.792 & 7.094 & 8.911 \\
\hline $6-7-3$ & 7.292 & 8.250 & 7.769 \\
\hline $6-8-3$ & 8.795 & 8.382 & 9.129 \\
\hline $6-9-3$ & 9.887 & 8.620 & 8.523 \\
\hline $6-10-3$ & 7.936 & 8.656 & 8.814 \\
\hline $6-11-3$ & 7.393 & 9.947 & 8.415 \\
\hline
\end{tabular}

Berdasarkan tabel 2, diperoleh informasi bahwa arsitektur 6-2-3 memiliki rataan nilai MSE paling kecil pada setiap percobaan. Selain itu, arsitektur 6-2-3 juga memiliki rataan nilai MSE yang paling stabil yaitu memiliki perbedaan nilai yang paling kecil pada setiap percobaan dibandingkan dengan 10 arsitektur lainnya. Oleh karena itu, arsitektur 6-2-3 terpilih sebagai arsitektur terbaik dan akan digunakan dalam proses prediksi data uji. 


\subsection{Memprediksi Perubahan Derajat Miopia}

Arsitektur ANN 6-2-3 yang telah terpilih selanjutnya digunakan untuk memprediksi perubahan derajat miopia. Prediksi dilakukan dengan cara memasukkan data uji yang terpilih pada bagian 3.4.

Berdasarkan informasi pada tabel 2, percobaan III pada arsitektur 6-2-3 memiliki rataan nilai MSE terkecil dibandingkan dua percobaan lainnya pada arsitektur yang sama. Dengan demikian, percobaan III dilanjutkan untuk memprediksi output. Total iterasi dari arsitektur ANN 6-2-3 pada proses prediksi adalah 40 iterasi sesuai dengan nilai maksimum iterasi yang ditetapkan. Hasil prediksi ketiga variabel $y$ pada setiap iterasi ANN 6-2-3 ini masih dalam bentuk derajat keanggotaan fuzzy. Diperoleh hasil prediksi akhir (pada iterasi ke-40) yaitu: $\mu\left(y_{1}\right)=0.19083636, \mu\left(y_{2}\right)=0.26651727$, dan $\mu\left(y_{3}\right)=0.20787108$.

\subsection{Un-scaling Hasil Prediksi}

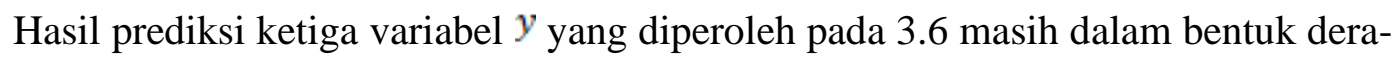
jat keanggotaan fuzzy. Untuk itu, hasil prediksi tersebut perlu dikonversikan kembali ke dalam bentuk bilangan real yang mewakili keadaan sebenarnya. Proses konversi ini dilakukan melalui tahap un-scaling. Un-scaling dilakukan dengan cara menghitung nilai $y_{1}, y_{2}$, dan $y_{3}$ menggunakan persamaan (10), (11), dan (12) dengan memanfaatkan nilai $\mu\left(y_{1}\right), \mu\left(y_{2}\right)$, dan $\mu\left(y_{3}\right)$ yang diperoleh pada 3.6. Hasil dari un-scaling ini berupa hasil prediksi akhir (pada iterasi ke-40) yang sebenarnya, yaitu:

$$
\begin{aligned}
& y_{1}=1.12210906 \approx 1.1 \text { Dioptri, } \\
& y_{2}=1.215284748 \approx 1.2 \text { Dioptri, } \\
& \text { dan } y_{3}=2.33577613 \approx 2.3 \text { Dioptri. }
\end{aligned}
$$

Perhatikan bahwa data uji sebelum melalui proses scaling, yaitu $x_{1}=29, x_{2}=0, x_{3}=3, x_{4}=5, x_{5}=5$, dan $x_{6}=10.5$. Dengan memperhatikan makna dari setiap variabel, makna dari hasil prediksi yang telah diperoleh dapat dijelaskan sebagai berikut: Seorang penderita miopia dengan kriteria:

1. Berumur 29 tahun;

2. Kedua orang tuanya bukan penderita miopia;

3. Membaca buku atau media cetak lainnya rata-rata selama 3 jam per hari;

4. Menatap layar perangkat elektronik rata-rata selama 5 jam per hari;

5. Menghabiskan waktunya dengan melakukan kegiatan di luar ruangan rata-rata selama 5 jam per hari. 
Dalam kurun waktu 10.5 tahun, derajat miopia pada mata kanannya diprediksi meningkat sebesar 1.1 Dioptri dan derajat miopia pada mata kirinya diprediksi mengalami peningkatan sebesar 1.2 Dioptri. Dengan kata lain, akumulasi peningkatan derajat miopia dari orang tersebut dalam kurun waktu 10.5 tahun adalah 2.3 Dioptri.

\subsection{Penghitungan Akurasi Hasil Prediksi}

Pada tahap ini dilakukan penghitungan akurasi hasil prediksi pada masing-masing variabel output yang diperoleh dengan arsitektur ANN 6-2-3. Penghitungan akurasi tersebut dilakukan dengan rumus persentase error sesuai persamaan (3). Diperoleh persentase error untuk $y_{i}\left(E_{\bar{i}}\right)$ dari ketiga hasil prediksi akhir (pada iterasi ke-40) yaitu: $E_{1}=12.21 \%, E_{2}=21.53 \%$, dan $E_{3}=16.79 \%$. Hal ini berarti akurasi hasil prediksi akhir variabel $y_{1}, y_{2}$, dan $y_{3}$ terhadap data uji berturut-turut sebesar $87.79 \%, 78.47 \%$, dan $83.21 \%$.

Lebih lanjut, diperoleh rata-rata nilai persentase error setiap iterasi yaitu: rataan $E_{1}=26.20 \%$, rataan $E_{2}=24.70 \%$, dan rataan $E_{3}=23.81 \%$. Hal ini berarti rataan akurasi hasil prediksi akhir variabel $y_{1^{1}}, y_{2^{\prime}}$ dan $y_{3}$ terhadap data uji pada setiap iterasinya berturut-turut sebesar $73.80 \%, 75.30 \%$, dan $76.19 \%$.

\section{Kesimpulan dan Saran}

\subsection{Simpulan}

Penelitian ini telah memprediksi perubahan derajat miopia dari seorang penderita miopia berdasarkan faktor-faktor penyebab miopia. Faktor-faktor penyebab miopia yang dipertimbangkan yaitu faktor-faktor yang berkaitan dengan identitas dan kebiasaan individu yang bersangkutan, di antaranya: umur, riwayat miopia orang tua, lama aktivitas pada jarak dekat (menatap layar perangkat elektronik dan membaca buku atau media cetak lainnya) dalam sehari, lama kegiatan di luar ruangan dalam sehari, dan rentang waktu penggantian kacamata. Seorang penderita miopia dengan umur 29 tahun, kedua orang tuanya bukan penderita miopia, serta memiliki kebiasaan berikut: membaca buku atau media cetak lainnya rata-rata selama 3 jam per hari, menatap layar perangkat elektronik rata-rata selama 5 jam per hari, menghabiskan waktunya dengan melakukan kegiatan di luar ruangan rata-rata selama 5 jam per hari, diprediksi bahwa derajat miopia pada mata kanannya akan mengalami perubahan yaitu meningkat sebesar 
1.1 Dioptri dalam kurun waktu 10.5 tahun dan derajat miopia pada mata kirinya diprediksi mengalami perubahan yaitu meningkat sebesar 1.2 Dioptri dalam kurun waktu 10.5 tahun. Dengan kata lain, akumulasi peningkatan derajat miopia dari orang tersebut dalam kurun waktu 10.5 tahun adalah 2.3 Dioptri. Akurasi dari hasil prediksi tersebut berturut-turut sebesar $87.79 \%, 78.47 \%$, dan $83.21 \%$.

\subsection{Saran}

Salah satu kelemahan dari penelitian ini adalah tidak mencoba jenis fungsi aktivasi selain sigmoid biner dan tidak mencoba beragam nilai maksimal iterasi pada ANN. Untuk itu, penelitian selanjutnya disarankan untuk mempertimbangkan penggunaan fungsi aktivasi jenis lain dan nilai maksimal iterasi yang lebih beragam. Lebih lanjut, penulis juga menyarankan agar memperdalam studi pustaka sehingga mendapatkan pilihan dan batasan-batasan yang lebih sesuai untuk fungsi keanggotaan fuzzy yang digunakan.

Selain itu, penelitian ini dapat dikembangkan lebih lanjut, misalnya dibuat dalam bentuk aplikasi. Dengan demikian, apabila menginginkan untuk memprediksi perubahan derajat miopia pada orang yang berbeda, maka pengguna aplikasi tersebut tinggal mengganti data uji yang digunakan.

\section{Daftar Pustaka}

[1] Badieah, Gernowo, R., \& Surarso, B. (2016). Metode Jaringan Syaraf Tiruan untuk Prediksi Performa Mahasiswa pada Pembelajaran Berbasis Problem Based Learning (PBL). Jurnal Sistem Informasi Bisnis, 6(1), 46-58. https://doi.org/10.21456/vol6iss1pp46-58

[2] Bethesda, Sperduto, R. D., Hiller, R., Podgor, M. J., Freidlin, V., Milton, R. C., ... Wilson, P. W. F. (1996). Familial Aggregation and Prevalence of Myopia in the Framingham Offspring Eye Study. Arch Ophthalmol, 114(3), 326-332. https://doi.org/10.1001/archopht.1996.01100130322017

[3] BPS. (2013). Proyeksi Penduduk Indonesia 2010-2035. Jakarta.

[4] Greene, P. R., Grill, Z. W., \& OD, A. M. (2015). Exploring Reading Glasses to Stabilize College Myopia. JSM Ophthalmology, 3(3), 1034.

[5] Greene, P. R., \& Medved, V. (2017). Progressive Myopia Dynamics: Analog Computer Model of Refraction Development. JSM Ophthalmology, 5(3), 1058.

[6] Heaton, J. (2008). Introduction to Neural Networks for C\#. (WordsRU.com, Ed.) (Second, Vol. 2). St. Louis: Heaton Research, Inc.

[7] Holden, B. A., Fricke, T. R., Wilson, D. A., Jong, M., Naidoo, K. S., Sankaridurg, P., ... Resnikoff, S. (2016). Global Prevalence of Myopia and High Myopia and Temporal Trends from 2000 through 2050. Ophthalmology, 123(5), 1036-1042. 
https://doi.org/10.1016/j.ophtha.2016.01.006

[8] Huang, L., Kawasaki, H., Liu, Y., \& Wang, Z. (2019). The Prevalence of Myopia and The Factors Associated with it Among University Students in Nanjing. Medicine, 98(10), $1-7$. https://doi.org/http://dx.doi.org/10.1097/MD.0000000000014777

[9] Klein, B. E. K. (2010). Epidemiology of Myopia and Myopic Shift in Refraction. In R. W. Beuerman, S.-M. Saw, D. T. H. Tan, \& T.-Y. Wong (Eds.), Myopia: Animal Models to Clinical Trials (pp. 3-21). Singapore: World Scientific Publishing Co. Pte. Ltd. Retrieved from https://books.google.com/books?id=NvUxxiM524EC

[10] Kusumadewi, S. (2004). Membangun Jaringan Syaraf Tiruan Menggunakan MATLAB \& Excel Link. (F. W. Nurwiyati, Ed.) (Pertama). Yogyakarta: Penerbit Graha Ilmu.

[11] Kusumadewi, S., \& Purnomo, H. (2010). Aplikasi Logika Fuzzy untuk Pendukung Keputusan (2nd ed.). Yogyakarta: Penerbit Graha Ilmu.

[12] Lim, L. T., Gong, Y., Ah-kee, E. Y., Xiao, G., Zhang, X., \& Yu, S. (2014). Impact of Parental History of Myopia on the Development of Myopia in Mainland China School-Aged Children. Ophthalmology and Eye Diseases, 6, 31-35. https://doi.org/10.4137/OED.S16031

[13] Medina, A. (2015). The Progression of Corrected Myopia. Graefes Arch Clin Exp Ophthalmol, 253, 1273-1277. https://doi.org/10.1007/s00417-015-2991-5

[14] Panchal, G., Ganatra, A., Shah, P., \& Panchal, D. (2011). Determination of Overlearning and Overfitting Problem in Backpropagation Neural Network. International Journal on Soft Computing, 2(2), 40-51.

[15] Saxena, R., Vashist, P., Tandon, R., Pandey, R. M., Bhardawaj, A., Gupta, V., \& Menon, V. (2017). Incidence and Progression of Myopia and Associated Factors in Urban School Children in Delhi: The North India Myopia Study (NIM Study). PLoS ONE, 12(12), 1-12. https://doi.org/https://doi.org/10.1371/journal.pone.0189774

[16] Saxena, R., Vashist, P., Tandon, R., Pandey, R. M., Bhardawaj, A., Menon, V., \& Mani, K. (2015). Prevalence of Myopia and Its Risk Factors in Urban School Children in Delhi: The North India Myopia Study ( NIM Study ). PLoS ONE, 10(2), 1-11. https://doi.org/10.1371/journal.pone.0117349

[17] Shanmuganathan, S. (2016). Artificial Neural Network Modelling. (S. Samarasinghe, Ed.). Switzerland: Springer International Publishing. https://doi.org/10.1007/978-3-319-28495-8

[18] Sibi, P., Jones, S. A., \& Siddarth, P. (2013). Analysis of Different Activation Functions Using Back Propagation Neural Networks. Journal of Theoretical and Applied Information Technology, 47(3), 1264-1268.

[19] Theophanous, C., Modjtahedi, B. S., Batech, M., Marlin, D. S., Luong, T. Q., \& Fong, D. s. (2018). Myopia Prevalence and Risk Factors in Children. Clinical Ophthalmology, 12, 1581-1587. 
[20] Vitale, S., Ellwein, L., Cotch, M. F., Ferris, F. L., \& Sperduto, R. (2008). Prevalence of Refractive Error in The United States, 1999-2004. Arch Ophthalmol, $126(8)$, 1111-1119. https://doi.org/10.1001/archopht.126.8.1111.Prevalence

[21] Welch, S. (2015). Neural Networks Demystified. Retrieved May 12, 2019, from https://github.com/stephencwelch/Neural-Networks-Demystified

[22] Williams, K. M., Bertelsen, G., Cumberland, P., Wolfram, C., Verhoeven, V. J. M., Anastasopoulos, E., ... Delcourt, C. (2015). Increasing Prevalence of Myopia in Europe and the Impact of Education. American Academy of Ophthalmology, 122(7), 1489-1497. https://doi.org/10.1016/j.ophtha.2015.03.018 